\title{
Influenza Vaccination Coverage Among Pregnant Women — United States, 2016-17 Influenza Season
}

\begin{abstract}
Helen Ding, MD ${ }^{1}$; Carla L. Black, PhD ${ }^{1}$; Sarah Ball, ScD ${ }^{2}$; Rebecca V. Fink, MPH²; Walter W. Williams, MD ${ }^{1}$; Amy Parker Fiebelkorn, MSN, MPH${ }^{1}$;
\end{abstract} Peng-Jun Lu, MD, PhD ${ }^{1}$; Katherine E. Kahn, $\mathrm{MPH}^{1}$; Denise V. D’Angelo, MPH${ }^{3}$; Rebecca Devlin, $\mathrm{MA}^{2}$; Stacie M. Greby, DVM ${ }^{1}$

Pregnant women and their infants are at increased risk for severe influenza-associated illness (1), and since 2004, the Advisory Committee on Immunization Practices (ACIP) has recommended influenza vaccination for all women who are or might be pregnant during the influenza season, regardless of the trimester of the pregnancy (2). To assess influenza vaccination coverage among pregnant women during the 2016-17 influenza season, CDC analyzed data from an Internet panel survey conducted during March 28-April 7, 2017. Among 1,893 survey respondents pregnant at any time during October 2016-January 2017, 53.6\% reported having received influenza vaccination before $(16.2 \%)$ or during $(37.4 \%)$ pregnancy, similar to coverage during the preceding four influenza seasons. Also similar to the preceding influenza season, $67.3 \%$ of women reported receiving a provider offer for influenza vaccination, $11.9 \%$ reported receiving a recommendation but no offer, and $20.7 \%$ reported receiving no recommendation; among these women, reported influenza vaccination coverage was $70.5 \%, 43.7 \%$, and $14.8 \%$, respectively. Among women who received a provider offer for vaccination, vaccination coverage differed by race/ethnicity, education, insurance type, and other sociodemographic factors. Use of evidence-based practices such as provider reminders and standing orders could reduce missed opportunities for vaccination and increase vaccination coverage among pregnant women.*

Since 2011, an Internet panel survey has been conducted for CDC by Abt Associates, Inc. (Cambridge, Massachusetts) at the beginning of each April to provide end-of-season estimates of influenza vaccination coverage among pregnant women and assess factors associated with vaccination. The Internet panel $^{\dagger}$ and survey methodology have been described previously (3). The 2016-17 survey was conducted during March 28-April 7, 2017, among women aged 18-49 years who reported being pregnant at any time since August 1, 2016. Among 10,734 women who entered the survey site, 2,399 were eligible and 2,319 completed the survey (a cooperation rate of 96.7\%). $\$$

\footnotetext{
${ }^{*}$ Guide to Community Preventive Services: Vaccination; https://www. thecommunityguide.org/topic/vaccination.

$\dagger$ Additional information on the online survey and incentives for participants is available at https://www.surveysampling.com.

${ }^{\S}$ An opt-in Internet panel survey is a nonprobability sampling survey. The denominator for a response rate calculation cannot be determined because no sampling frame with a selection probability is involved at the recruitment stage. Instead, the survey cooperation rate is provided.
}

Data were weighted to reflect the age, race/ethnicity, and geographic distribution of the total U.S. population of pregnant women. A woman was considered to be vaccinated for the 2016-17 season if she reported receiving vaccination before or during her most recent pregnancy since July 1, 2016. Analysis was limited to 1,893 women who reported being pregnant any time during the peak influenza vaccination period (October 2016-January 2017). A difference was noted as an increase or decrease when a $\geq 5$ percentage-point difference occurred between any values being compared. 9

Influenza vaccination coverage among pregnant women in 2016-17 was similar to coverage during the previous four seasons (Figure). Among women pregnant during the 2016-17 influenza season, 53.6\% reported receiving influenza vaccination before $(16.2 \%)$ or during $(37.4 \%)$ pregnancy since July 1, 2016 (Table 1). Coverage among women aged 18-24 years $(41.7 \%)$ was lower than coverage among women aged $25-34$ years $(58.4 \%)$ and $35-49$ years $(58.5 \%)$. Coverage among Hispanic women $(61.2 \%)$ was higher than that among non-Hispanic white (white) women (55.4\%) and non-Hispanic black (black) women (42.3\%); these differences were not observed during the 2015-16 season. Higher vaccination coverage was found among women with higher level of education, married women, women with private or military insurance, working women, women at or above poverty level, women with a high-risk condition, women with positive attitude toward vaccination effectiveness or safety, and women who were concerned about influenza infection, similar to the 2015-16 season.

The proportion of women who reported receiving a provider recommendation for and offer** of vaccination was $67.3 \%$ in the 2016-17 season, similar to that during the past four seasons (Figure). During both the 2015-16 and 2016-17 seasons, women who reported receiving both a provider recommendation for and offer of influenza vaccination had higher vaccination coverage $(63.4 \%$ [2015-16] and 70.5\%

\footnotetext{
9 Additional information on obstacles to inference in nonprobability samples is available at http://www.aapor.org/Education-Resources/Reports/NonProbability-Sampling.aspx.

** "Recommendation and offer" is based on a "yes" response to the question "Since July 2016, during any of your visits to a doctor, nurse, or medical professional, did any of these medical professionals offer to give you a flu vaccination during a visit?"
} 
FIGURE. Prevalence of provider recommendation for and offer of influenza vaccination* and influenza vaccination coverage ${ }^{\dagger}$ among women pregnant any time during October-January — Internet panel survey, United States, 2010-11 through 2016-17 influenza seasons

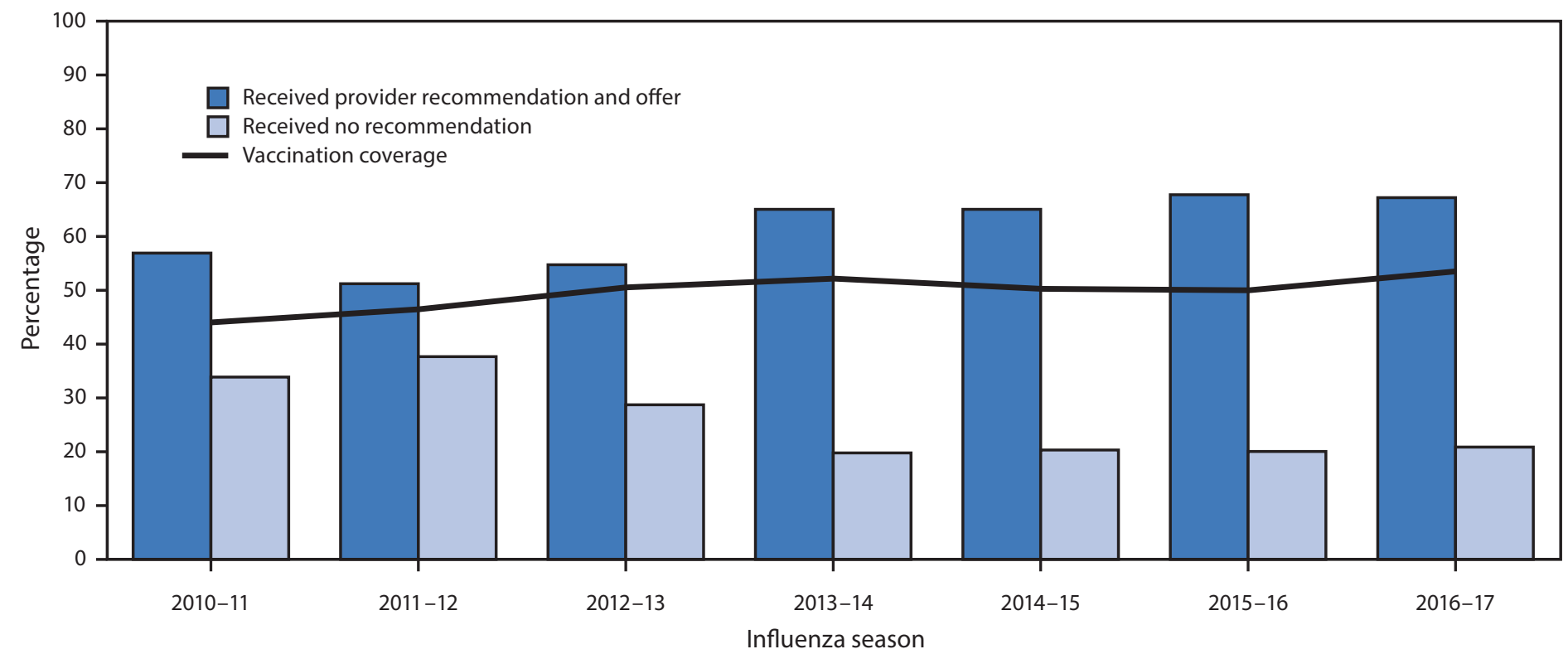

\footnotetext{
* Among women who reported having at least one visit to a provider since July.

' Vaccination coverage estimates for the 2012-13 through 2016-17 influenza seasons were based on vaccination given from July to mid-April; coverage estimates for the 2010-11 and 2011-12 influenza seasons were based on vaccination given from August to mid-April.
}

[2016-2017]) compared with women who reported receiving a provider recommendation but no offer ${ }^{\dagger \dagger}(37.5 \%$ and $43.7 \%)$ and women who reported receiving no recommendation for vaccination ${ }^{\$ \$}(12.8 \%$ and $14.8 \%)$ (Table 1$)$; this pattern was observed among all age groups, racial/ethnic groups, levels of education, marital status, some level of insurance coverage, poverty status, number of health care visits, presence or absence of a high-risk condition, attitudes regarding efficacy and safety of influenza vaccine, and concern about influenza infection (Table 2). An increased number of provider visits since July 2016 was associated with both an increase in women's report of receiving a provider recommendation and an increase in vaccination coverage estimates $(65.7 \%$ [ $1-5$ visits]; $70.9 \%$ [6-10 visits]; 72.1\% [>10 visits]). Women in the following subgroups reported receiving a provider recommendation for and offer of vaccination less frequently than did women in the

\footnotetext{
†† "Recommendation but no offer" is based on a "yes" response to the question "Since July 2016, during any of your visits to a doctor, nurse, or other medical professional, did any of these medical professionals recommend that you get a flu vaccination or tell you that you needed a flu vaccination?" and a "no" response to the question "Since July 2016, during any of your visits to a doctor, nurse, or medical professional, did any of these medical professionals offer to give you a flu vaccination during a visit?"

$\$ \$$ "No recommendation" is based on a "no" response to the questions "Since July 2016, during any of your visits to a doctor, nurse, or other medical professional, did any of these medical professionals recommend that you get a flu vaccination or tell you that you needed a flu vaccination?" and "Since July 2016, during any of your visits to a doctor, nurse, or medical professional, did any of these medical professionals offer to give you a flu vaccination during a visit?"
}

reference category of each stratum: aged $18-24$ years, with a college degree, without medical insurance, without a highrisk condition other than pregnancy, with a negative attitude toward influenza vaccination effectiveness or safety, or not concerned about influenza infection (Table 2).

Vaccination coverage differed within some subgroups that reported similar proportions of receipt of a provider recommendation for and offer of vaccination. For example, although $68 \%-69 \%$ of insured women reported being offered vaccination, coverage was $74.7 \%$ among women with private or military insurance and $63.9 \%$ among women with public insurance. Differences in coverage among women who were offered vaccination were also observed between white and black women and women with more than a college degree and those with a college degree or less (Table 2). Among insured women who were offered vaccination, a higher proportion of publically insured women were younger (18-24 years), black, had less than a college degree, and lived below the poverty threshold compared with privately insured women.

Among the $221(11.9 \%)$ women who reported that their provider recommended but did not offer vaccination, 114 $(51.0 \%)$ received a referral99 to go somewhere else to be vaccinated; $36.7 \%$ of the women receiving a referral were vaccinated,

\footnotetext{
99 Referral is defined based on a "yes" response to the question "Did any doctor, nurse, or medical professional suggest that you go someplace else to get the flu vaccination?"
} 
TABLE 1. Influenza vaccination coverage before and during pregnancy among women pregnant any time during October-January, by selected characteristics, Internet panel surveys, United States, 2016-17 and 2015-2016 influenza seasons

\begin{tabular}{|c|c|c|c|c|c|c|c|}
\hline \multirow[b]{2}{*}{ Characteristic } & \multicolumn{3}{|c|}{ 2015-16 influenza season } & \multicolumn{3}{|c|}{ 2016-17 influenza season } & \multirow{2}{*}{$\begin{array}{l}\text { Percentage point difference } \\
\text { in vaccination coverage } \\
2016-17 \text { to } 2015-16\end{array}$} \\
\hline & Unweighted no. & Weighted \% & $\begin{array}{l}\text { Vaccinated, } \\
\text { weighted } \%\end{array}$ & Unweighted no. & Weighted \% & $\begin{array}{l}\text { Vaccinated, } \\
\text { weighted } \%\end{array}$ & \\
\hline Total & 1,692 & - & 49.9 & 1,893 & - & 53.6 & 3.7 \\
\hline Vaccinated before pregnancy & 239 & - & 14.1 & 292 & - & 16.2 & 2.1 \\
\hline Vaccinated during pregnancy & 605 & - & 35.8 & 750 & - & 37.4 & 1.6 \\
\hline \multicolumn{8}{|l|}{ Age group (yrs) } \\
\hline $18-24$ & 417 & 28.9 & 49.4 & 464 & 28.6 & $41.7^{*}$ & $-7.7^{\dagger}$ \\
\hline $25-34$ & 981 & 53.6 & 49.8 & 1,087 & 53.8 & 58.4 & $8.6^{\dagger}$ \\
\hline $35-49^{\S}$ & 294 & 17.5 & 51.2 & 342 & 17.6 & 58.5 & $7.3^{\dagger}$ \\
\hline \multicolumn{8}{|l|}{ Race/Ethnicity } \\
\hline Hispanic & 366 & 22.1 & 51.8 & 257 & 21.5 & $61.2^{*}$ & $9.3^{\dagger}$ \\
\hline Black, non-Hispanic & 277 & 19.8 & 49.4 & 262 & 20.8 & $42.3^{*}$ & $-7.1^{\dagger}$ \\
\hline White, non-Hispanic ${ }^{\S}$ & 898 & 50.4 & 49.0 & 1,200 & 50.2 & 55.4 & $6.4^{\dagger}$ \\
\hline Other, non-Hispanic & 151 & 7.7 & 52.1 & 174 & 7.5 & 51.7 & -0.4 \\
\hline \multicolumn{8}{|l|}{ Education } \\
\hline <College degree & 872 & 53.1 & $46.5^{*}$ & 672 & 37.9 & $47.3^{*}$ & 0.8 \\
\hline College degree & 642 & 36.8 & $52.6^{*}$ & 910 & 46.4 & $52.7^{*}$ & 0.1 \\
\hline$>$ College degree ${ }^{\S}$ & 178 & 10.2 & 58.2 & 311 & 15.7 & 71.7 & $13.6^{\dagger}$ \\
\hline \multicolumn{8}{|l|}{ Married } \\
\hline $\mathrm{Yes}^{\S}$ & 1,044 & 59.8 & 53.5 & 1,386 & 70.2 & 56.7 & 3.2 \\
\hline No & 648 & 40.2 & $44.6^{*}$ & 507 & 29.8 & $46.4^{*}$ & 1.8 \\
\hline \multicolumn{8}{|l|}{ Insurance coverage } \\
\hline Any public & 672 & 41.3 & $46.8^{*}$ & 568 & 32.9 & $47.6^{*}$ & 0.8 \\
\hline Private/Military only ${ }^{\S}$ & 983 & 56.6 & 53.5 & 1,250 & 63.0 & 59.3 & $5.8^{\dagger}$ \\
\hline No insurance & 37 & 2.1 & $14.9^{*}$ & 75 & 4.1 & $14.6^{*}$ & -0.3 \\
\hline \multicolumn{8}{|l|}{ Working status ${ }^{\Uparrow}$} \\
\hline Yes $^{\S}$ & 950 & 56.1 & 53.9 & 1,239 & 65.4 & 57.1 & 3.2 \\
\hline No & 742 & 43.9 & $44.9^{*}$ & 654 & 34.6 & $47.2^{*}$ & 2.3 \\
\hline \multicolumn{8}{|l|}{ Poverty status** } \\
\hline At or above poverty & 1,312 & 76.4 & 52.0 & 1,688 & 88.2 & 55.1 & 3.2 \\
\hline Below poverty & 377 & 23.6 & $43.1^{*}$ & 204 & 11.8 & $42.5^{*}$ & -0.6 \\
\hline \multicolumn{8}{|l|}{ High-risk condition ${ }^{\dagger \dagger}$} \\
\hline Yes $^{\S}$ & 728 & 43.0 & 55.6 & 729 & 38.2 & 63.3 & $7.7^{\dagger}$ \\
\hline No & 964 & 57.0 & $45.7^{*}$ & 1,164 & 61.8 & $47.7^{*}$ & 2.0 \\
\hline \multicolumn{8}{|c|}{ Number provider visits since July } \\
\hline None & 10 & 0.6 & —§§ & 69 & 4.3 & $6.1^{*}$ & \\
\hline $1-5$ & 326 & 19.6 & $39.5^{*}$ & 430 & 22.6 & $39.8^{*}$ & 0.3 \\
\hline $6-10$ & 706 & 41.5 & $50.0^{*}$ & 720 & 37.9 & 58.8 & $8.7^{\dagger}$ \\
\hline$>10^{\S}$ & 650 & 38.3 & 55.7 & 674 & 35.2 & 62.7 & $7.0^{\dagger}$ \\
\hline
\end{tabular}

See table footnotes on next page.

compared with only $12.5 \%$ of women who received a provider recommendation but no offer or referral.

\section{Discussion}

Influenza vaccination coverage among pregnant women in 2016-17 was $53.6 \%$, similar to coverage in the $2012-13$ through 2015-16 influenza seasons. Similar to the past three seasons, $67.3 \%$ of pregnant women in 2016-17 reported receiving a provider recommendation for and offer of vaccination. Although the Standards for Adult Immunization Practice (4) support recommendation for and offer of influenza vaccination, the percentage of currently or recently pregnant women who reported receiving a provider recommendation and offer has not changed during the last four influenza seasons. This might be partly attributable to differences in perception among patients and providers of a recommendation for or offer of vaccination. In a recent survey of obstetric care providers conducted by the American College of Obstetricians and Gynecologists (ACOG), all surveyed providers reported that they recommend influenza vaccine to their pregnant patients; however, only $85 \%$ of patients surveyed at the same practices reported receiving a recommendation for vaccination, suggesting that although providers believe they are giving a recommendation for vaccination, the recommendation might not be communicated effectively (5).

Vaccination differences were seen by race/ethnicity, concerns about vaccination and influenza, insurance status, and number of provider visits. As has previously been observed, black women had lower vaccination coverage and Hispanic women had higher vaccination coverage compared with white women, despite similar percentages among each racial/ethnic group reporting a provider 
TABLE 1. (Continued) Influenza vaccination coverage before and during pregnancy among women pregnant any time during October-January, by selected characteristics, Internet panel surveys, United States, 2016-17 and 2015-2016 influenza seasons

\begin{tabular}{|c|c|c|c|c|c|c|c|}
\hline \multirow[b]{2}{*}{ Characteristic } & \multicolumn{3}{|c|}{ 2015-16 influenza season } & \multicolumn{3}{|c|}{ 2016-17 influenza season } & \multirow{2}{*}{$\begin{array}{l}\text { Percentage point difference } \\
\text { in vaccination coverage } \\
2016-17 \text { to } 2015-16\end{array}$} \\
\hline & Unweighted no. & Weighted \% & $\begin{array}{l}\text { Vaccinated, } \\
\text { weighted } \%\end{array}$ & Unweighted no. & Weighted \% & $\begin{array}{l}\text { Vaccinated, } \\
\text { weighted \% }\end{array}$ & \\
\hline \multicolumn{8}{|c|}{ Provider recommendation/offer ${ }^{\text {ๆๆ }}$} \\
\hline Recommended and offered ${ }^{\S}$ & 1,133 & 67.6 & 63.4 & 1,238 & 67.3 & 70.5 & $7.1^{\dagger}$ \\
\hline Recommended with no offer & 218 & 12.5 & $37.5^{*}$ & 221 & 11.9 & $43.7^{*}$ & $6.2^{\dagger}$ \\
\hline No recommendation & 331 & 19.9 & $12.8^{*}$ & 363 & 20.7 & $14.8^{*}$ & 2.0 \\
\hline \multicolumn{8}{|c|}{ Attitude toward effectiveness of influenza vaccination $* * *$} \\
\hline Positive ${ }^{\S}$ & 1,313 & 77.9 & 61.8 & 1,473 & 77.8 & 65.8 & 4.0 \\
\hline Negative & 379 & 22.1 & $8.0^{*}$ & 420 & 22.2 & $10.8^{*}$ & 2.8 \\
\hline \multicolumn{8}{|c|}{ Attitude toward safety of influenza vaccination ${ }^{\dagger+\dagger}$} \\
\hline Positive ${ }^{\S}$ & 1,265 & 74.6 & 62.8 & 1,467 & 75.4 & 66.9 & 4.1 \\
\hline Negative & 427 & 25.4 & $12.2^{*}$ & 426 & 24.6 & $12.9^{*}$ & 0.7 \\
\hline \multicolumn{8}{|c|}{ Attitude toward influenza infection $§ \S \S$} \\
\hline Concerned $^{\S}$ & 1,059 & 62.9 & 54.0 & 1,231 & 64.6 & 58.8 & 4.7 \\
\hline Not concerned & 633 & 37.1 & $43.0^{*}$ & 662 & 35.4 & $44.3^{*}$ & 1.3 \\
\hline
\end{tabular}

$* \geq 5$ percentage-point difference compared with reference group.

$\dagger \geq 5$ percentage-point difference from 2015-16 to 2016-17 influenza season.

$\S$ Reference group for comparison within subgroups.

"Women who were employed for wages and self-employed were categorized as working; those who were out of work, homemakers, students, retired, or unable to work were categorized as not working.

${ }^{* *}$ As determined by the U.S. Census Bureau (https://www.census.gov/data/tables/time-series/demo/income-poverty/historical-poverty-thresholds.html). For 2016-17 season, below poverty $=$ a total of annual family income $<\$ 24,339$ for a family of four with two minors as of 2016; for 2015-16 season, below poverty $=$ total family income of $<\$ 24,036$ for a family of four with two minors as of 2015.

t+ Conditions associated with increased risk for serious medical complication from influenza, including chronic asthma, a lung condition other than asthma, a heart condition, diabetes, a kidney condition, a liver condition, obesity, or a weakened immune system caused by a chronic illness or by medicines taken for a chronic illness.

$\S \S$ Vaccination coverage estimates were suppressed because sample size was $<30$.

१ๆ Excluded women who had no provider visit since July $2016(n=69)$ for 2016-17 influenza season and women who had no provider visit since July 2016 ( $n=10)$ for 2015-16 influenza season.

*** Created based on two questions regarding attitudes toward effectiveness of influenza vaccination:"Flu vaccine is somewhat/very effective in preventing flu"; and "Flu vaccine a pregnant woman received is somewhat/very effective in protecting her baby from the flu." One point was given for each "yes" answer for either of the two questions. Respondents with a summary score of 1 or 2 were considered to have a"positive" attitude, and those with a summary score of 0 were considered to have a "negative" attitude.

${ }^{\mathrm{tt+}}$ Created based on three questions regarding the safety of influenza vaccination: "Flu vaccination is somewhat/very/completely safe for most adult women"; "Flu vaccination is somewhat/very/completely safe for pregnant women"; and "Flu vaccination that a pregnant woman receives is somewhat/very/completely safe for her baby." One point was given for each "yes" answer for any of the three questions. Respondents who had a summary score of 2 or 3 were considered to have a "positive" attitude, and those with a summary score of 1 or less were considered to have a "negative" attitude.

$\S \S \S$ Created based on response to three questions regarding attitudes regarding influenza infection: "If a pregnant women gets the flu, it is somewhat/very likely to harm the baby"; "Flu infection during pregnancy is somewhat/very likely harm pregnant women"; and "Flu infection during pregnancy somewhat/very likely harm her baby." One point was given for each "yes" answer for any of the three questions. Respondents who had a summary score of 2 or 3 were considered to be "concerned" and those with a summary score of 1 or less were considered to be "not concerned."

recommendation for and offer of vaccination (3). One study found that racial differences in vaccination coverage among pregnant women persisted after adjustment for a provider recommendation for or offer of influenza vaccination, insurance status, and demographic factors ( $($ ), and another study suggests that racial disparities might be caused by differences in sociocultural norms, misperception of effectiveness and safety of vaccination, and vaccination resistance and hesitancy $(\nearrow)$, or could be modified or confounded by other factors such as age, education, or insurance status.

Although many women reported concerns about the safety or effectiveness of vaccination, these women were more likely to be vaccinated when there was a provider recommendation and offer compared with women with vaccination concerns who did not receive a vaccination recommendation from their provider, underscoring the need for providers to educate and counsel all pregnant patients. Although vaccination coverage increased with number of provider visits, 37\% of women who had more than 10 visits were not vaccinated, indicating missed vaccination opportunities. Assessing vaccination status at every clinical encounter and providing an effective recommendation for and offer of vaccination can help ensure that more pregnant women receive influenza vaccine during pregnancy (4). ACOG has developed a toolkit to assist providers in integrating vaccination services and effective recommendations into their practice, including communication strategies and other resources.***

In this report, vaccination coverage was lower among pregnant women with public health insurance than among those with private or military insurance, at each level of provider recommendation

\footnotetext{
*** http://immunizationforwomen.org/providers/resources/toolkits/ immunization.php.
} 
TABLE 2. Percentage of women receiving a provider recommendation/offer of influenza vaccination and self-reported influenza vaccination coverage, by provider recommendation and offer among women who visited a provider at least once since July 2016 and who were pregnant any time during October 2016-January 2017 - Internet Panel Survey, United States, 2016-17 influenza season

\begin{tabular}{|c|c|c|c|c|c|c|c|c|c|c|}
\hline \multirow[b]{3}{*}{ Characteristic } & \multicolumn{4}{|c|}{$\begin{array}{c}\text { Provider recommendation } \\
\text { for/offer of } \\
\text { influenza vaccination }\end{array}$} & \multicolumn{6}{|c|}{ Vaccination coverage } \\
\hline & \multirow{2}{*}{$\begin{array}{l}\text { Unweighted } \\
\text { no. }\end{array}$} & \multirow{2}{*}{$\begin{array}{l}\text { Recommended, } \\
\text { offered, } \\
\text { weighted } \%\end{array}$} & \multirow{2}{*}{$\begin{array}{l}\text { Recommended, } \\
\text { no offer, } \\
\text { weighted } \%\end{array}$} & \multirow{2}{*}{$\begin{array}{l}\text { No } \\
\text { recommendation, } \\
\text { weighted \% }\end{array}$} & \multicolumn{2}{|c|}{$\begin{array}{l}\text { Provider recommended, } \\
\text { offered }\end{array}$} & \multicolumn{2}{|c|}{$\begin{array}{c}\text { Provider recommended, } \\
\text { no offer }\end{array}$} & \multicolumn{2}{|c|}{ No recommendation } \\
\hline & & & & & $\begin{array}{l}\text { Unweighted } \\
\text { no. }\end{array}$ & $\begin{array}{c}\text { Weighted } \\
\%\end{array}$ & $\begin{array}{c}\text { Unweighted } \\
\text { no. }\end{array}$ & $\begin{array}{c}\text { Weighted } \\
\%\end{array}$ & $\begin{array}{c}\text { Unweighted } \\
\text { no. }\end{array}$ & $\begin{array}{c}\text { Weighted } \\
\%\end{array}$ \\
\hline Total & 1,822 & 67.3 & 11.9 & 20.7 & 1,238 & 70.5 & 221 & 43.7 & 363 & 14.8 \\
\hline \multicolumn{11}{|l|}{ Age group (yrs) } \\
\hline $18-24$ & 408 & $61.0^{*}$ & 10.6 & $28.3^{*}$ & 249 & $65.2^{*}$ & 46 & $26.7^{*}$ & 113 & 14.8 \\
\hline 25-34 & 1,074 & 69.1 & 12.6 & 18.3 & 746 & 72.6 & 136 & 49.6 & 192 & 14.5 \\
\hline $35-49^{\dagger}$ & 340 & 71.1 & 11.7 & 17.2 & 243 & 71.1 & 39 & 46.9 & 58 & 15.8 \\
\hline \multicolumn{11}{|l|}{ Race/Ethnicity } \\
\hline Hispanic & 254 & 70.1 & 9.1 & 20.8 & 181 & $75.8^{*}$ & 23 & $-\S$ & 50 & $21.5^{*}$ \\
\hline $\begin{array}{l}\text { Black, } \\
\text { non-Hispanic }\end{array}$ & 216 & 64.4 & 12.3 & 23.3 & 137 & $64.9^{*}$ & 25 & $-\S$ & 54 & 9.8 \\
\hline $\begin{array}{l}\text { White, } \\
\text { non-Hispanic }{ }^{\dagger}\end{array}$ & 1,180 & 67.7 & 13.0 & 19.3 & 807 & 70.8 & 153 & 44.6 & 220 & 13.6 \\
\hline $\begin{array}{l}\text { Other, } \\
\text { non-Hispanic }\end{array}$ & 172 & 64.1 & 12.2 & 23.7 & 113 & 65.7 & 20 & $-\S$ & 39 & 16.6 \\
\hline \multicolumn{11}{|l|}{ Education } \\
\hline $\begin{array}{l}<\text { College } \\
\text { degree }\end{array}$ & 660 & 67.6 & 10.2 & 22.2 & 443 & $62.0^{*}$ & 69 & $30.3^{*}$ & 148 & $13.3^{*}$ \\
\hline College degree & 853 & $65.4^{*}$ & 12.3 & 22.3 & 573 & $73.6^{*}$ & 106 & $41.6^{*}$ & 174 & $15.0^{*}$ \\
\hline $\begin{array}{l}>\text { College }^{+} \\
\text {degree }^{\dagger}\end{array}$ & 309 & 71.9 & 15.1 & 13.0 & 222 & 82.1 & 46 & 70.2 & 41 & 20.3 \\
\hline \multicolumn{11}{|l|}{ Married } \\
\hline Yes $^{\dagger}$ & 1,330 & 68.4 & 12.9 & 18.7 & 920 & 73.1 & 172 & 51.1 & 238 & 15.3 \\
\hline No & 492 & 65.0 & 9.6 & 25.4 & 318 & $64.3^{*}$ & 49 & $20.9^{*}$ & 125 & 14.0 \\
\hline \multicolumn{11}{|c|}{ Insurance coverage } \\
\hline $\begin{array}{l}\text { Private/Military } \\
\text { only }^{\dagger}\end{array}$ & 1,221 & 68.3 & 12.8 & 18.9 & 847 & 74.7 & 163 & 48.7 & 211 & 17.8 \\
\hline Any public & 540 & 69.3 & 10.4 & 20.3 & 371 & $63.9^{*}$ & 53 & $31.8^{*}$ & 116 & $12.0^{*}$ \\
\hline No insurance & 61 & $30.2^{*}$ & 9.8 & 60.0 & 20 & — $^{\S}$ & 5 & —§ & 36 & 6.2 \\
\hline \multicolumn{11}{|l|}{ Working status ${ }^{\pi}$} \\
\hline Yes $^{\dagger}$ & 1,176 & 68.0 & 12.3 & 19.7 & 803 & 74.8 & 152 & 49.8 & 221 & 17.4 \\
\hline No & 646 & 66.2 & 11.3 & 22.5 & 435 & $62.7^{*}$ & 69 & $32.0^{*}$ & 142 & $10.8^{*}$ \\
\hline \multicolumn{11}{|l|}{ Poverty status** } \\
\hline $\begin{array}{l}\text { At or above } \\
\text { poverty }^{\dagger}\end{array}$ & 1,624 & 66.7 & 12.3 & 21.0 & 1,099 & 73.0 & 203 & 46.9 & 322 & 14.5 \\
\hline Below poverty & 197 & $72.2^{*}$ & 8.9 & 18.9 & 138 & $54.1^{*}$ & 18 & -§ & 41 & 17.6 \\
\hline
\end{tabular}

See table footnotes on next page.

for or offer of vaccination; frequency of provider recommendation or offer was similar for women with public and private or military insurance. This was also found among women with less than a college degree compared with women with more than a college degree. Lower vaccination coverage has been reported among pregnant women with public insurance (8) and women with lower levels of education (3). ${ }^{\dagger \dagger}$ Further work is needed to understand and address barriers to receipt of influenza vaccination by pregnant women covered by public insurance and with less than a college degree.

The findings in this report are subject to at least four limitations. First, a nonprobability sample that did not include women without Internet access was used in the analysis; therefore, results are not

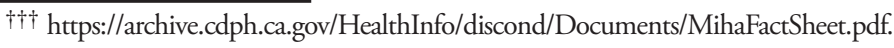

generalizable to all pregnant women in the United States. Second, vaccination status was self-reported and might be subject to recall bias or social desirability bias. Third, because the Internet panel survey is an opt-in survey, estimates might be biased if a woman's decision to join the internet panel or participate in this particular survey were related to receipt of vaccination. Vaccination coverage estimates from the Internet panel survey have been consistently 5-10 percentage points higher than estimates from the less timely probability-based National Health Interview Survey. However, both surveys have found similar stable trends with no increasing coverage. $\$ \$ \$$ Strengths and limitations of the Internet panel survey compared with probability sampling surveys can be found

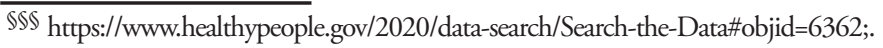


TABLE 2. (Continued) Percentage of women receiving a provider recommendation/offer of influenza vaccination and self-reported influenza vaccination coverage, by provider recommendation and offer among women who visited a provider at least once since July 2016 and who were pregnant any time during October 2016-January 2017 - Internet Panel Survey, United States, 2016-17 influenza season

\author{
Provider recommendation \\ for/offer of \\ influenza vaccination
}

\begin{tabular}{|c|c|c|c|c|c|c|c|c|c|c|}
\hline \multirow[b]{3}{*}{ Characteristic } & \multicolumn{4}{|c|}{$\begin{array}{c}\text { Provider recommendation } \\
\text { for/offer of } \\
\text { influenza vaccination }\end{array}$} & \multicolumn{6}{|c|}{ Vaccination coverage } \\
\hline & \multirow[b]{2}{*}{$\begin{array}{l}\text { Unweighted } \\
\text { no. }\end{array}$} & \multirow{2}{*}{$\begin{array}{l}\text { Recommended, } \\
\text { offered, } \\
\text { weighted } \%\end{array}$} & \multirow{2}{*}{$\begin{array}{l}\text { Recommended, } \\
\text { no offer, } \\
\text { weighted \% }\end{array}$} & \multirow{2}{*}{$\begin{array}{l}\text { No } \\
\text { recommendation, } \\
\text { weighted \% }\end{array}$} & \multicolumn{2}{|c|}{$\begin{array}{l}\text { Provider recommended, } \\
\text { offered } \\
\end{array}$} & \multicolumn{2}{|c|}{$\begin{array}{l}\text { Provider recommended, } \\
\text { no offer }\end{array}$} & \multicolumn{2}{|c|}{ No recommendation } \\
\hline & & & & & $\begin{array}{l}\text { Unweighted } \\
\text { no. }\end{array}$ & $\begin{array}{l}\text { Weighted } \\
\%\end{array}$ & $\begin{array}{l}\text { Unweighted } \\
\text { no. }\end{array}$ & $\begin{array}{l}\text { Weighted } \\
\%\end{array}$ & $\begin{array}{l}\text { Unweighted } \\
\text { no. }\end{array}$ & $\begin{array}{c}\text { Weighted } \\
\%\end{array}$ \\
\hline \multicolumn{11}{|c|}{ High-risk condition ${ }^{\dagger+}$} \\
\hline Yes $^{\dagger}$ & 724 & 75.1 & 10.3 & 14.6 & 546 & 75.3 & 74 & 48.5 & 104 & 14.1 \\
\hline No & 1,098 & $62.2^{*}$ & 13.0 & 24.8 & 692 & $66.7^{*}$ & 147 & $41.3^{*}$ & 259 & 15.1 \\
\hline \multicolumn{11}{|c|}{ Number of provider visits since July 2016} \\
\hline $1-5$ & 429 & $48.3^{*}$ & 13.5 & 38.3 & 217 & $65.7^{*}$ & 58 & $25.4^{*}$ & 154 & $12.2^{*}$ \\
\hline $6-10$ & 720 & 71.4 & 11.8 & 16.8 & 517 & 70.9 & 85 & $46.0^{*}$ & 118 & 16.1 \\
\hline$>10^{\dagger}$ & 673 & 75.2 & 11.1 & 13.7 & 504 & 72.1 & 78 & 55.3 & 91 & 17.8 \\
\hline \multicolumn{11}{|c|}{ Attitude toward efficacy of influenza vaccination $\S \S$} \\
\hline Positive $^{\dagger}$ & 1,430 & 72.0 & 11.4 & 16.7 & 1,037 & 80.5 & 164 & 54.5 & 229 & 22.4 \\
\hline Negative & 392 & $50.3^{*}$ & 14.1 & 35.7 & 201 & $17.9^{*}$ & 57 & $11.7^{*}$ & 134 & $1.9^{*}$ \\
\hline \multicolumn{11}{|c|}{ Attitude toward safety of influenza vaccination } \\
\hline Positive $^{\dagger}$ & 1,421 & 73.8 & 11.6 & 14.6 & 1,047 & 80.4 & 169 & 56.3 & 205 & 22.6 \\
\hline Negative & 401 & $47.0^{*}$ & 13.0 & 40.0 & 191 & $21.3^{*}$ & 52 & $8.1^{*}$ & 158 & $5.9^{*}$ \\
\hline \multicolumn{11}{|c|}{ Attitude toward influenza infection ${ }^{* * *}$} \\
\hline Concerned $^{\dagger}$ & 1,182 & 70.1 & 11.5 & 18.4 & 839 & 74.5 & 139 & 50.7 & 204 & 17.7 \\
\hline Not concerned & 640 & $62.3^{*}$ & 12.8 & 25.0 & 399 & $62.5^{*}$ & 82 & $32.4^{*}$ & 159 & $11.0^{*}$ \\
\hline
\end{tabular}

$* 2$ percentage point difference compared with reference group.

† Reference group for comparisons within subgroups.

$\S$ Vaccination coverage estimates were suppressed because sample size was $<30$.

" Persons who were employed for wages and self-employed were categorized as working. Those who were out of work, homemakers, students, retired, or unable to work were categorized as not working.

** As determined by the U.S. Census Bureau (https://www.census.gov/data/tables/time-series/demo/income-poverty/historical-poverty-thresholds.html). For 2016-17 season, below poverty $=$ a total of annual family income $<\$ 24,339$ for a family of four with two minors as of 2016.

${ }^{+\dagger}$ Conditions associated with increased risk for serious medical complication from influenza, including chronic asthma, a lung condition other than asthma, a heart condition, diabetes, a kidney condition, a liver condition, obesity, or a weakened immune system caused by a chronic illness or by medicines taken for a chronic illness.

$\S \S$ Created based on two questions regarding attitudes toward influenza vaccination: "Flu vaccine is somewhat/very effective in preventing flu"; and "Flu vaccine a pregnant women received is somewhat/very effective in protecting her baby from the flu." 1 point was given for each "yes" answer for either of the two questions. Respondents with a summary score of 1 or 2 were defined to have a "positive" attitude, and those with a summary score of 0 were defined to have a "negative" attitude.

१ศ Created based on three questions regarding the safety of influenza vaccination: "Flu vaccination is somewhat/very/completely safe for most adult women"; "Flu vaccination is somewhat/very/completely safe for pregnant women"; and "Flu vaccination that a pregnant women receives is somewhat/very/completely safe for her baby." 1 point was given for each "yes" answer for any of the three questions. Respondents who had a summary score of 2 or 3 were defined to have a "positive" attitude, and those with a summary score of 1 or less were defined to have a "negative" attitude.

*** Created based on response to three questions regarding attitude toward influenza infection:"If a pregnant women gets the flu, it is somewhat/very likely to harm the baby"; "Flu infection during pregnancy somewhat/very likely harm pregnant women"; and "Flu infection during pregnancy somewhat/very likely harm her baby." 1 point was given for each "yes" answer for any of the three questions. Respondents who had a summary score of 2 or 3 were defined as "Concerned" and those with a summary score of 1 or less were defined as "Not concerned."

elsewhere (9). Finally, the composite variables computed for attitudes toward influenza vaccination and infection were not validated.

Findings in this report support evidence that a provider's recommendation for and offer of influenza vaccination to pregnant women is associated with receipt of vaccination. Women who were referred to another provider for vaccination were more likely to be vaccinated than women who did not receive an offer or referral. The Standards for Adult Immunization Practices call for all providers to strongly recommend needed vaccines and either administer vaccines or refer patients to a provider who can administer them (4). ACOG and Text4Baby 999 provide

\footnotetext{
999 https://www.text4baby.org
}

resources to ensure recommendations are provided effectively to help women receive influenza vaccination as early as possible during pregnancy. Vaccination coverage of pregnant women can be increased by a combination of 1) implementation of evidencebased practices (e.g., provider reminders and standing orders for vaccination) to ensure that influenza vaccination is recommended and offered at each visit before and during pregnancy or that the patient is referred to an influenza vaccine provider, and 2) clinical education about the risk for influenza infection and safety and benefit of influenza vaccination (10). Further work is needed to understand differences in vaccination coverage among women who were offered vaccination by a provider. 


\section{Summary}

What is already known about this topic?

Pregnant women and infants are at increased risk for influenzarelated complications and hospitalization. Vaccinating pregnant women can reduce their risk for influenza-related respiratory illness and reduce the risk for influenza in their infants aged $<6$ months. A provider recommendation for and offer of vaccination is associated with higher vaccination coverage among pregnant women.

What is added by this report?

Analysis of data from a 2017 Internet panel survey indicates that in the 2016-17 influenza season, 53.6\% of pregnant women were vaccinated before or during pregnancy, similar to the 2015-16 season. Prevalence of provider recommendation for and offer of vaccination were similar to those in the last four influenza seasons. Most women who reported receiving both a provider recommendation for and offer of influenza vaccination had high vaccination coverage $(70.5 \%)$, but this varied for those with public insurance (63.9\%) and by other sociodemographic factors.

What are the implications for public health practice?

To improve protection from complications of influenza for mothers and infants, measures to improve vaccination coverage are needed. Implementing the Standards for Adult Immunization Practice, which recommend all health care providers assess, recommend, administer or refer, and document vaccinations, can help ensure pregnant women are fully vaccinated. Evidence-based practices such as provider reminders and standing orders can help implement these standards and reduce missed opportunities for vaccination.

\section{Acknowledgment}

Carolyn Bridges, U.S. Public Health Service, Retired.

\section{Conflict of Interest}

No conflicts of interest were reported.

\begin{abstract}
${ }^{1}$ Immunization Services Division, National Center for Immunization and Respiratory Diseases, CDC; ${ }^{2} \mathrm{Abt}$ Associates, Inc., Cambridge, Massachusetts; ${ }^{3}$ Division of Reproductive Health, National Center for Chronic Disease Prevention and Health Promotion, CDC.
\end{abstract}

Corresponding author: Helen Ding, hding@cdc.gov, 404-639-8513.

\section{References}

1. Rasmussen SA, Jamieson DJ, Uyeki TM. Effects of influenza on pregnant women and infants. Am J Obstet Gynecol 2012;207(3 Suppl):S3-8.

2. Grohskopf LA, Sokolow LZ, Broder KR, et al. Prevention and control of influenza with vaccines: recommendations of the Advisory Committee on Immunization Practices (ACIP), United States, 2016-17 influenza season. MMWR Recomm Rep 2016;65(No. RR-05). https://doi. org/10.15585/mmwr.rr6505al

3. Ding $\mathrm{H}$, Black CL, Ball S, et al. Influenza vaccination coverage among pregnant women-United States, 2014-15 influenza season. MMWR Morb Mortal Wkly Rep 2015;64:1000-5. https://doi.org/10.15585/ mmwr.mm6436a2

4. Orenstein WA, Gellin BG, Beigi RH, et al.; National Vaccine Advisory Committee. Recommendations from the National Vaccine Advisory committee: standards for adult immunization practice. Public Health Rep 2014;129:115-23. https://doi.org/10.1177/003335491412900203

5. Stark LM, Power ML, Turrentine M, et al. Influenza vaccination among pregnant women: patient beliefs and medical provider practices. Infect Dis Obstet Gynecol 2016;2016:3281975. https://www.hindawi.com/ journals/idog/2016/3281975/2016.

6. Ahluwalia IB, Ding H, Harrison L, D'Angelo D, Singleton JA, Bridges C; Pregnancy Risk Assessment Monitoring System Influenza Working Group. Disparities in influenza vaccination coverage among women with live-born infants: PRAMS surveillance during the 2009-2010 influenza season. Public Health Rep 2014;129:408-16. https://doi. org/10.1177/003335491412900504

7. Lindley MC, Wortley PM, Winston CA, Bardenheier BH. The role of attitudes in understanding disparities in adult influenza vaccination. Am J Prev Med 2006;31:281-5. https://doi.org/10.1016/j.amepre.2006.06.025

8. Koepke R, Kahn D, Petit AB, et al. Pertussis and influenza vaccination among insured pregnant women-Wisconsin, 2013-2014. MMWR Morb Mortal Wkly Rep 2015;64:746-50.

9. Kennedy ED, Ahluwalia IB, Ding H, Lu P-J, Singleton JA, Bridges CB. Monitoring seasonal influenza vaccination coverage among pregnant women in the United States. Am J Obstet Gynecol 2012;207(Suppl):S9-16. https://doi.org/10.1016/j.ajog.2012.06.069

10. Mazzoni SE, Brewer SE, Pyrzanowski JL, et al. Effect of a multi-modal intervention on immunization rates in obstetrics and gynecology clinics. Am J Obstet Gynecol 2016;214:617.e1-7. https://doi.org/10.1016/j. ajog.2015.11.018 